\title{
Article \\ Green Synthesis of Ag Nanoparticles for Plasmon-Assisted Photocatalytic Degradation of Methylene Blue
}

\author{
Ying Ma ${ }^{1, *}$, Liyiming Tao ${ }^{1}$, Shi Bai ${ }^{2}$ and Anming $\mathrm{Hu}^{3, *(D)}$ \\ 1 School of Mechanical Engineering \& Automation, Beihang University, 37 Xueyuan Road, Haidian District, \\ Beijing 100191, China; taoliyiming@buaa.edu.cn \\ 2 Advanced Laser Processing Research Team, RIKEN Center for Advanced Photonics, 2-1 Hirosawa, Wako, \\ Saitama 351-0198, Japan; shi.bai@riken.jp \\ 3 Advanced Manufacturing and Nanoengineering Lab, 578 Violet Street, Waterloo, ON N2V 2V6, Canada \\ * Correspondence: yingma@buaa.edu.cn (Y.M.); anming.hu@uwaterloo.ca (A.H.)
}

check for

updates

Citation: Ma, Y.; Tao, L.; Bai, S.; Hu, A. Green Synthesis of Ag Nanoparticles for Plasmon-Assisted Photocatalytic Degradation of Methylene Blue. Catalysts 2021, 11, 1499. https://doi.org/10.3390/ catal11121499

Received: 30 October 2021 Accepted: 8 December 2021 Published: 10 December 2021

Publisher's Note: MDPI stays neutral with regard to jurisdictional claims in published maps and institutional affiliations.

Copyright: (c) 2021 by the authors. Licensee MDPI, Basel, Switzerland. This article is an open access article distributed under the terms and conditions of the Creative Commons Attribution (CC BY) license (https:/ / creativecommons.org/licenses/by/ $4.0 /)$.

\begin{abstract}
Green synthesis of metal nanoparticles has been gaining great interest due to the increasing need for eco-friendly manufacturing and application of nanomaterials. Metal nanoparticles, especially silver nanoparticles, are widely used in water treatments and as environmental remedy. Here we present a method to synthesize silver nanoparticles at room temperature using green tea extract under visible light irradiation, along with an application for enhanced photocatalytic degradation on methylene blue (MB) dye. Ag nanoparticles were synthesized under different photoreduction times and then further characterized. The photocatalytic rate of synthesized nanoparticles was also investigated and compared with $\mathrm{TiO}_{2}$ nanowires under $\mathrm{UV}$ and visible light irradiations. The results showed that $\mathrm{Ag}$ nanoparticles can directly degrade $\mathrm{MB}$ dye through plasmonic excitation and electron transferring under visible light, and $\mathrm{Ag}$ nanoparticles can further enhance $\mathrm{TiO}_{2}$ photonic degradation by enhanced e-h separation with UV and/or a wide band light, including UV light. Ag nanoparticles under visible light photoreduction for $0.5 \mathrm{~h}$ presented better behavior for two kinds of plasmonic enhanced photodegradation; the average size of the nanoparticles is about $30 \mathrm{~nm}$. Therefore, the green synthesized Ag nanoparticles exhibit promising prospects in chemical and biological pollutant treatment.
\end{abstract}

Keywords: green synthesis; silver nanoparticles; photocatalytic activity

\section{Introduction}

Noble metal nanoparticles are being widely used in diverse areas such as microelectronics, medicine, and environment remedies due to both their unique electrical, optical and biological properties and special applications in areas such as catalysis, plasmonic devices, and biosensing [1,2]. Conventional synthesis of Ag NPs such as chemical reduction methods [3,4], often use toxic chemicals that may cause environmental risks $[3,5]$. Therefore, green synthesis of Ag NPs has many great advantages because of its facile and bio-friendly processes. In fact, over the past decade, a number of biologic procedures and/or syntheses with nontoxic organic compounds have been investigated for eco-friendly synthesis of silver nanoparticles. Microbe-mediated synthesis of Ag NPs was first reported by using Pseudomonas stutzeri AG259, which was isolated from silver mines, showing the ability to produce Ag NPs [6]. Diversity of bacteria (both gram-positive and gram-negative) were also employed for synthesizing of Ag NPs [7]. Besides bacteria, fungi also gained wide attention for synthesis of Ag NPs [8]. For example, the capping protein on the surface of white-rot fungus Anamorphous Bjerkandera sp. R1 played a determining role in the synthesis of Ag NPs [9]. Penicillium oxalicum 1-208 has proved useful for rapid extracellular biosynthesis of Ag NPs under light radiation [10]. Recently, plant-mediated synthesis was found to be a better choice for Ag NPs synthesis since microbe-mediated methods required the maintenance of highly aseptic conditions and preservation of microbe cultures [11]. 
Green Ag NPs are also synthesized using various nature products such as Tamarind fruit extract [12], potato (Solanum tuberosum) infusion [13], lxora coccinea leaves extract [14], eucalyptus leaf extract [15], and summer savory extract [16].

$\mathrm{TiO}_{2}$ is one of the most widely used semiconductor photocatalysts in water treatment due to its low cost, commercially available at various crystalline forms and other controllable material characteristics, such as high surface area, non-toxicity, and chemical stability [17]. Generally, photocatalysis occurs through the absorption of ultraviolet (UV) photo energy greater than the band gap energy of $\mathrm{TiO}_{2}\left(\mathrm{E}_{\mathrm{g}}, 3.2 \mathrm{eV}\right)$, the generated valence band holes and conduction band electrons can react with species adsorbed on the catalyst surface [18]. However, UV light only uses a small percentage of sunlight energy. Numerous studies have paid attention to visible sensitized photocatalytic activity of modified $\mathrm{TiO}_{2}$ in the degradation of industrial dyes, such as methylene blue (MB), as a model pollutant in mimicking sunlight-sensitized water treatment. Nitrogen-doped $\mathrm{TiO}_{2}$ has attracted considerable attention since it significantly improved the photocatalytic activities of $\mathrm{TiO}_{2}$ [19]. S. Jafari et al. [20] reported that modified $\mathrm{TiO}_{2}$ ( $\mathrm{N}$ and $\mathrm{S}$ forms) nanoparticles showed visible light absorption capability for the removal of $\mathrm{MB}$, as compared to unmodified $\mathrm{TiO}_{2}$. There are also numerous research works on other nonmetal-doped $\mathrm{TiO}_{2}$ as an effective method to improve visible light photocatalytic activities, such as C-doping [21], F-doping [22] and S-doping [23]. Rutile Iodine-doped $\mathrm{TiO}_{2}$ nanowires were reported to produce the highest methylene blue degradation under visible light excitation, compared to other synthesized non-metal doping nanomaterials, and the enhanced photocatalytic activity was attributed to existing oxygen vacancies, iodine multi-valences in I-O-Ti bonds, and $3 \mathrm{~d}_{\text {state }} \mathrm{Ti}^{3+}$ sites in the $\mathrm{TiO}_{2}$ lattice [24].

The deposition of noble metals (such as $\mathrm{Ag}, \mathrm{Au}, \mathrm{Pt}$, and $\mathrm{Pd}$ ) on a $\mathrm{TiO}_{2}$ surface can also enhance photocatalytic efficiency as electron traps promoting interfacial charge transfer processes in the composite systems [25]. Ag NPs embedded in $\mathrm{TiO}_{2}$ were proved to be efficient for MB removal under near-UV irradiation due to the enhanced near-field amplitudes of localized surface plasmon resonance (LSPR), which was named "plasmonic photocatalysis" [26]. Plasmonic photocatalysis has recently emerged as a promising technology for developing high performance visible-light driven photocatalysts [26,27]. The strong interaction between metal nanoparticles and light caused a collective oscillation of the conduction electrons on the metal surface, known as surface plasmon resonance (SPR) [28,29]. It usually results in strong light scattering and adsorption properties. As electron is trapped, plasmonic nanoparticles accelerate the separation process of the photogenerated electrons and holes in the semiconductor catalyst under visible light [27]. By absorbing photons at the wavelength corresponding to their plasmonic absorption bands, Ag NPs generated strong LSPR; thus, the bandgap excitation of the $\mathrm{TiO}_{2}$ particles nearby can be stimulated, therefore increasing the photocatalytic activity due to the generation of more electron-hole pairs [30]. The LSPR effect of the Ag NPs was determined by their particle size; with a larger particle size, a higher electric field can be induced due to the increasing LSPR strength [31]. Several methods have been found to prepare Ag-modified $\mathrm{TiO}_{2}$, but there are still some disadvantages in these conventional methods. The synthesis process usually requires either high pressure, energy, temperature, or toxic chemicals [32]. Furthermore, a photocatalytic mechanism with plasmonic particles is worth further investigation for optimization. To our knowledge, green synthesis of plasmonic-assisted photocatalytic degradation has not been reported yet.

In this study, a simple method to synthesize Ag NPs using tea extract is presented. Ag NPs were prepared with green tea extract at room temperature under visible light radiation and compared to thermal reduction. The effect of radiation time was evaluated to optimize the photocatalytic activity of synthesized Ag NPs. The plasmonic degradation of MB under visible light using Ag NPs was investigated and illustrated. To further confirm the plasmonic enhancement of Ag NPs under visible light, $\mathrm{TiO}_{2}$ nanowires were used to demonstrate enhanced photocatalytic activities. With different photonic degradation light sources, the degradation rate was also evaluated with or without $\mathrm{TiO}_{2}$ nanowires. 
The mechanism of plasmonic enhanced photonic degradation under visible light was demonstrated. The current results are beneficial in developing green chemistry to optimize photocatalytic degradation for water treatment.

\section{Results and Discussion}

\subsection{UV-Vis Spectroscopy and X-ray Diffraction}

Figure 1 shows the UV-Vis spectra of Ag NPs synthesized by heating and visible light irradiation for an hour, respectively. Since there is no other reducing agent in the system, the formation of Ag NPs can be attributed to the direct redox between tea extract and $\mathrm{Ag}^{+}$. The SPR spectra of Ag NPs synthesized by heating and visible light radiation were obtained at $456 \mathrm{~nm}$ and $489 \mathrm{~nm}$, respectively, due to silver clusters with different sizes and oxidation states. Ag NPs typically having plasmonic resonance wavelength $\left(\lambda_{\max }\right.$ values) in the visible range of $400-500 \mathrm{~nm}$ [33]. SPR absorbance is extremely sensitive to the size and shape of the nanoparticles and surrounding media [34]. The shift to longer wavelength and broadening of peak plasmon resonance indicate the increasing diameters of Ag NPs, and broad SPR can be attributed to different particle sizes and the formation of anisotropic particles [35]. In principle, spherical nanoparticles contribute a single SPR, whereas shape variation leads to an additional SPR bands at a longer wavelength [36]. Figure 1 shows a single SPR band, indicating that the spherical shape of synthesized Ag NPs is dominant, which was further confirmed by SEM observations (presented later).

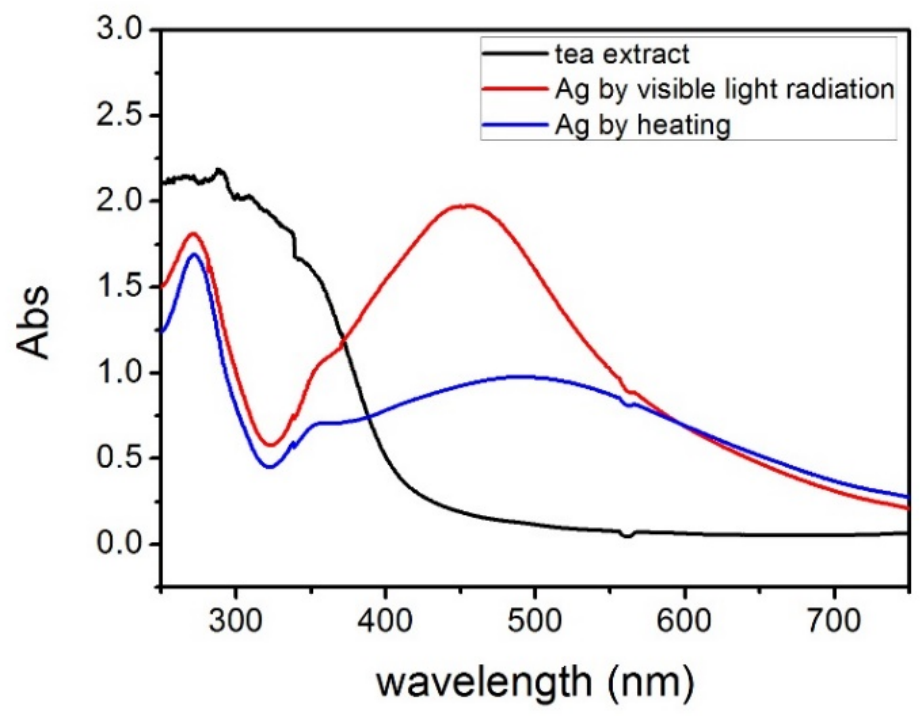

Figure 1. UV-Vis spectra of Ag NPs synthesized by heating up and visible light irradiation.

Figure 2 shows the XRD pattern of synthesized Ag NPs by visible light irradiation for an hour. The peaks at $38.26^{\circ}$ and $64.8^{\circ}$ are assigned to diffraction from (111) and (220) planes of face centered cubic silver (JCPD S No. 4-783). The XRD pattern illustrates that the synthesized Ag NPs are crystalline in nature. To avoid the sintering of silver nanoparticles during drying, the solution is relatively diluted. Therefore, the XRD pattern is remarkably noisy. According to the Scherrer formula $D=K \gamma / \beta \cos \theta$, where $K$ stands for the Scherrer's constant, $\gamma$ corresponds to the wavelength of $\mathrm{Cu} \mathrm{K} \alpha$ irradiation, $\beta$ is the Bragg diffraction angle (rad), and $\theta$ corresponds to the half width of the diffraction peak of the sample; thus, the average size of the synthesized Ag NPs is $34.6 \mathrm{~nm}$. 


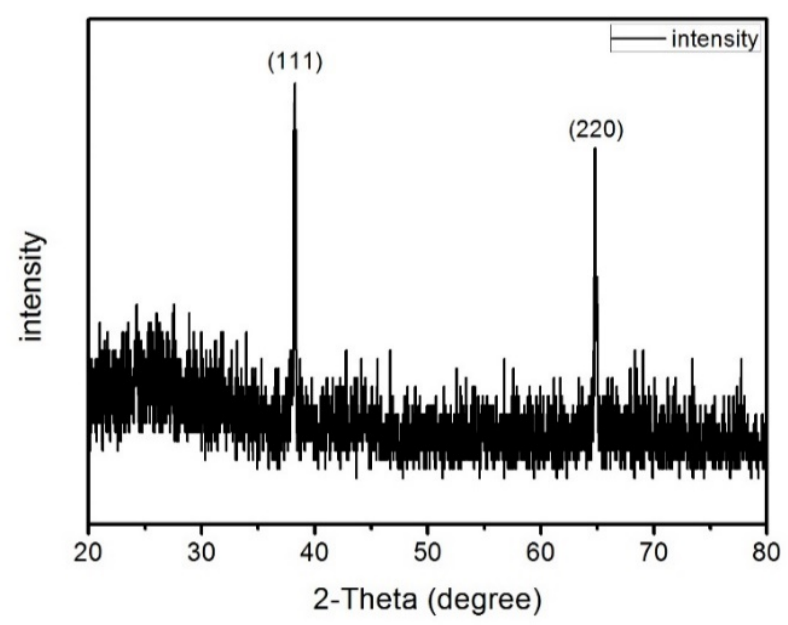

Figure 2. XRD pattern of Ag NPs.

\subsection{SEM Studies}

SEM was employed to analyze the morphology of Ag NPs and particle size distribution. The size distribution was evaluated by the statistical measurement of 100 arbitrarily chosen Ag NPs. Figure S1a showed the morphology of Ag NPs synthesized by heating with green tea extract as a reduction agent. The particle size was about $70 \mathrm{~nm}$. Some of the Ag NPs were anisotropic particles, attributed to the broadened SPR. These results are consistent with previous results with sodium citrate as a reduction reagent [4].

Figure S1b-e showed the structure of synthesized Ag NPs sample $2-5$ by visible light irradiation for different times $(0.5 \mathrm{~h}, 1 \mathrm{~h}, 1.5 \mathrm{~h}, 2 \mathrm{~h})$ and the statistic distribution of particle size. After $0.5 \mathrm{~h}$ visible light irradiation, the average size of synthesized Ag NPs sample 2 is about $25.3 \mathrm{~nm}$, while the average size of sample 3 reaches $32.9 \mathrm{~nm}$ after $1 \mathrm{~h}$ irradiation. And as the radiation time increases, the Ag NPs grow larger. The average size of samples 4 and 5 reaches $33.2 \mathrm{~nm}$ and $40.7 \mathrm{~nm}$, respectively, after $1.5 \mathrm{~h}$ and $2 \mathrm{~h}$ irradiation. Obviously, the silver nanoparticles remarkably coarsen with increasing irradiation time.

\subsection{IR Spectra and XPS Analysis of Organic Shells}

High resolution SEM images in Figure 3 show that the Ag NPs synthesized by visible light irradiation are covered by an organic layer. The thickness of this surface layer is about $8 \mathrm{~nm}$. This organic layer keeps the nanoparticle agglomerated. The composite of this outer layer was further characterized by IR spectra and XPS analysis.

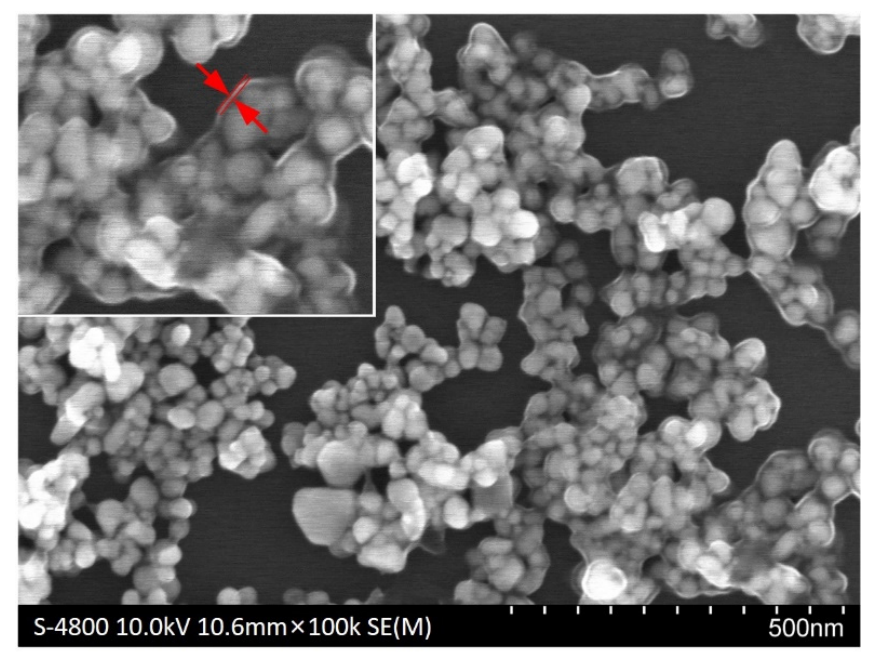

Figure 3. High resolution SEM image of Ag NPs with visible light irradiation time of $0.5 \mathrm{~h}$. Inset: local magnified images. The organic shell is clearly viewed. The two lines show the organic shell thickness. 
IR measurements were carried out to identify the potential functional groups of the surface layer, as shown in Figure 4. The band at $1632 \mathrm{~cm}^{-1}$ in the spectra correspond to $\mathrm{C}=\mathrm{C}$ groups or aromatic rings or $\mathrm{C}=\mathrm{O}$ stretching in the carboxyl group [16,37]. The band at $1384 \mathrm{~cm}^{-1}$ correspond to $-\mathrm{NO}_{2}$ aliphatic nitro groups [38]. The band at $1034 \mathrm{~cm}^{-1}$ corresponds to $-\mathrm{CN}$ - stretching of amines. The XPS analysis in Figure 5 showed that the composite cover on $\mathrm{Ag}$ NPs consists of the following elements: $\mathrm{C}, \mathrm{Na}, \mathrm{O}, \mathrm{Ca}, \mathrm{K}$ and $\mathrm{N}$. Thereinto, $\mathrm{C}, \mathrm{O}$ and $\mathrm{N}$ were elements detected from components of tea extract such as methylxanthines, polyphenols, theaflavins, amino acids and alkaloids, which contain $\mathrm{C}=\mathrm{C}$, $\mathrm{C}=\mathrm{O}$ and $-\mathrm{CN}-$. These assignments are consistent with the IR results [39]. $\mathrm{Na}, \mathrm{K}$ and $\mathrm{Ca}$ are trace elements which have been found in tea extract [40]. Si in the XPS spectra can be attributed to the Si substrate. Therefore, the surface organic layer can be attributed to the residual tea extract. Both polyphenols and methylxanthines could act as reducing agents for Ag reduction while other organic groups in the tea extract act like a capping agent for Ag NPs synthesis [41]. Due to the presence of a variety of plant constituents in tea extract, there are various alternative routes to reduce $\mathrm{Ag}^{+}$to $\mathrm{Ag}^{0}$, but the polyphenols play a better role as a reducing agent in tea extract. The main part of tea polyphenols is cianidanol, which contains numbers of the $-\mathrm{OH}$ group. It can easily release electrons to reduce $\mathrm{Ag}^{+}$to $\mathrm{Ag}^{0}$ on absorption of visible light. As shown in Figure 6, molecular changes are induced by charge transfer during the reduction of $\mathrm{Ag}^{+}$to $\mathrm{Ag}^{0}$, and the enol form is converted to the quinonoid form. This transformation releases two electrons by removing two hydrogen atoms from the enol form, thus reducing two $\mathrm{Ag}^{+}$to $\mathrm{Ag}^{0}$. These reduced silver atoms further form Ag NPs. Binding energy of Ag $3 d$ (Figure S2) showed that the sample was entirely made of $\mathrm{Ag}^{0}$ nanoparticles, with binding energy of $368.3 \mathrm{eV}$, consistent with $\mathrm{M}$. Romand's results [42].

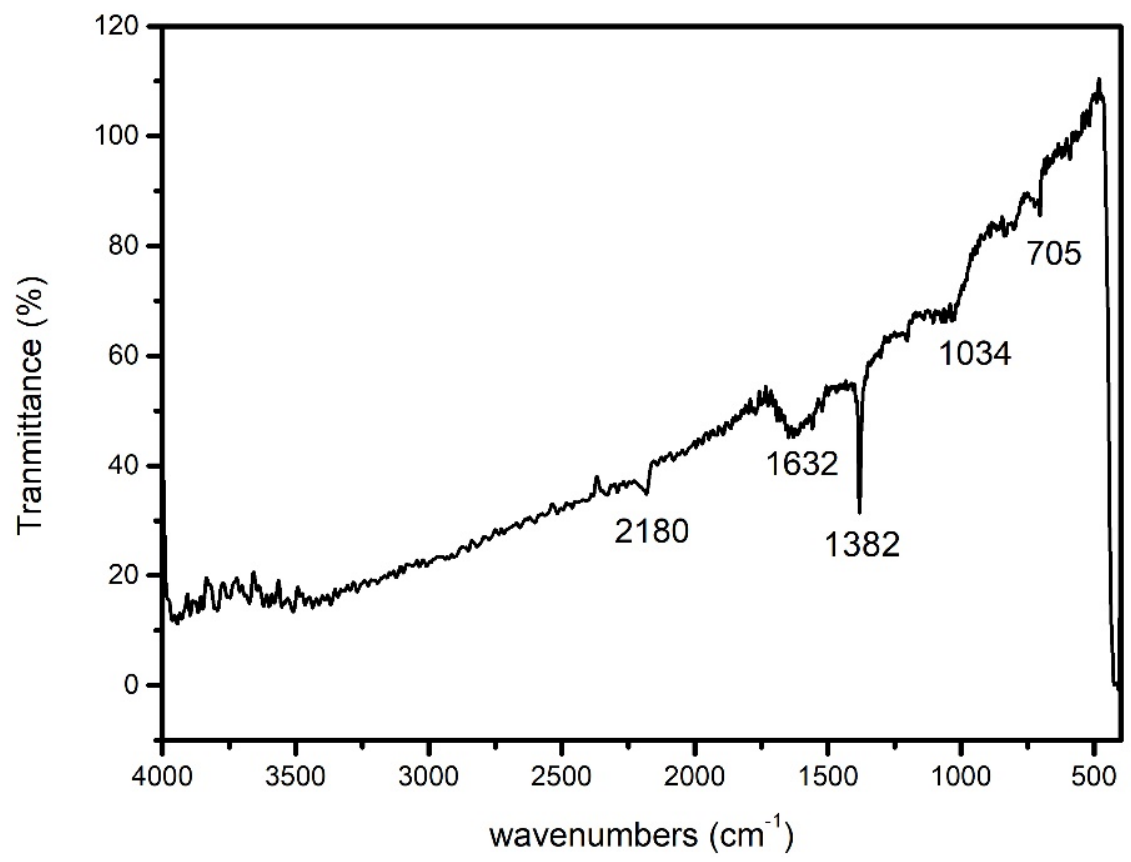

Figure 4. IR spectra of Ag NPs synthesized by visible light irradiation for $0.5 \mathrm{~h}$. 


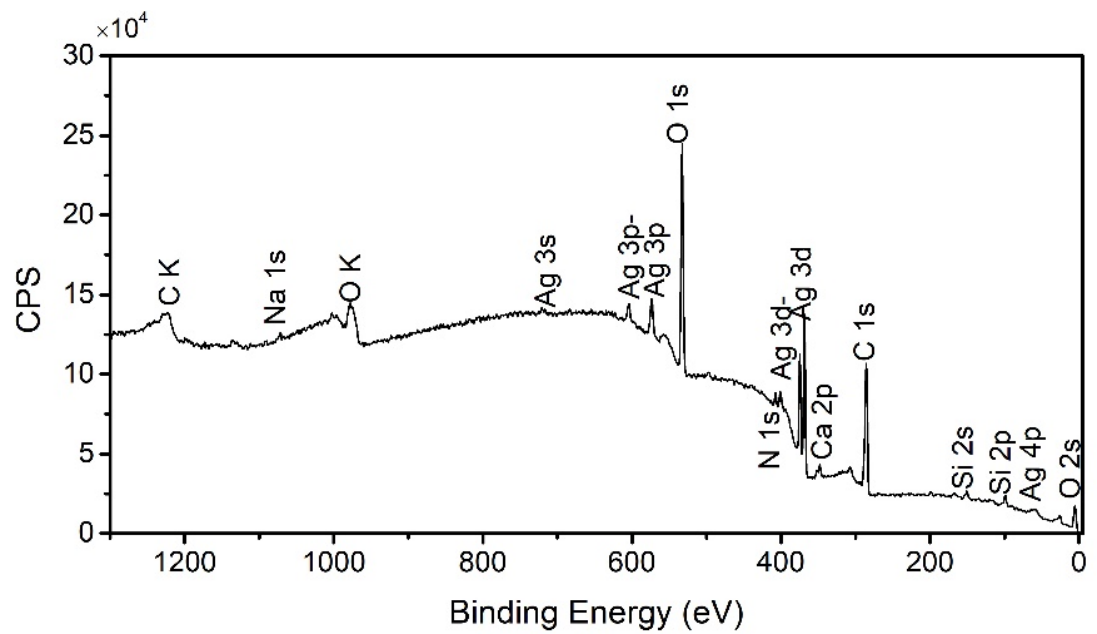

Figure 5. XPS analysis of the covered organic compound on Ag NPs with visible light irradiation time of $0.5 \mathrm{~h}$.

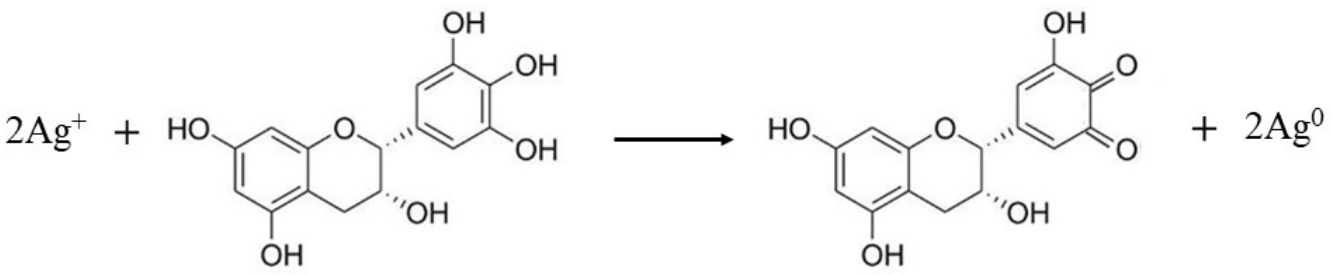

Figure 6. Photoinduced reduction of enol form of cianidanol molecule into the quinonoid form.

\subsection{Photocatalytic Degradation of $M B$}

Ag NPs possess lower loss and higher quality plasmon resonance than other metal NPs, under LSPR hot electrons transfer from Ag NPs to oxygen absorbed on the Ag NPs, which result in a negatively charged state of the oxygen-absorbed Ag nanostructure, and the hot electrons enhanced the catalytic oxidation reaction of plasmonic Ag NPs [43]. Green synthesized Ag NPs has been proven efficient for the degradation of MB under full spectrum sunlight [44], the calculated percentage of degradation efficiency was $95.3 \%$ after $72 \mathrm{~h}$ sunlight irradiation, but the photocatalytic degradation under visible light still remains unexplored. In this study, the visible light sensitized photocatalytic activity of synthesized Ag NPs was evaluated by degradation of MB under a sunlight simulator with a UV filter cut-off at $450 \mathrm{~nm}$. The absorption peak of MB was observed to be around $664 \mathrm{~nm}$. The reduction progress of the reaction was monitored by UV-Vis spectroscopy to track the changes in the absorption intensity at $664 \mathrm{~nm}$ at different time intervals [17]. The photocatalytic degradation can be described using a pseudo first-order kinetic model (Equation (1)) and its integrated form (Equation (2)):

$$
\begin{gathered}
-\frac{d C}{d t}=k_{a p} C \\
\ln \left(\frac{C}{C_{0}}\right)=k_{a p} t
\end{gathered}
$$

where $\mathrm{C}_{0}$ is the initial concentration, $\mathrm{C}$ is the concentration at time $\mathrm{t}, k_{a p}$ is the apparent rate constant. $\mathrm{A} \ln \left(\frac{\mathrm{C}}{\mathrm{C}_{0}}\right)$ versus $\mathrm{t}$ plot and a line of best fit yields $k_{a p}$ [45].

Figure 7a-e showed the UV-Vis spectra of degradation of MB under visible light irradiation using Ag NPs sample 1-5 and their degradation rate $\mathrm{K}\left(\mathrm{min}^{-1}\right)$ was calculated. All the samples reached equilibrium before irradiation. According to Figure 7a,e, the photolysis of MB under visible light irradiation can be negligible. The relationship between degradation rate $\mathrm{K}$ and synthesis method along with average particle size is summarized in 
Table 1. The table showed that by increasing irradiation time, the Ag NPs grow larger while the degradation rate $\mathrm{K}$ decreases. On the hand, with further shortening the illumination time, the concentration of silver nanoparticles is also significantly reduced. Therefore, to obtain better photocatalytic activity, the average size of Ag NPs should be optimized.
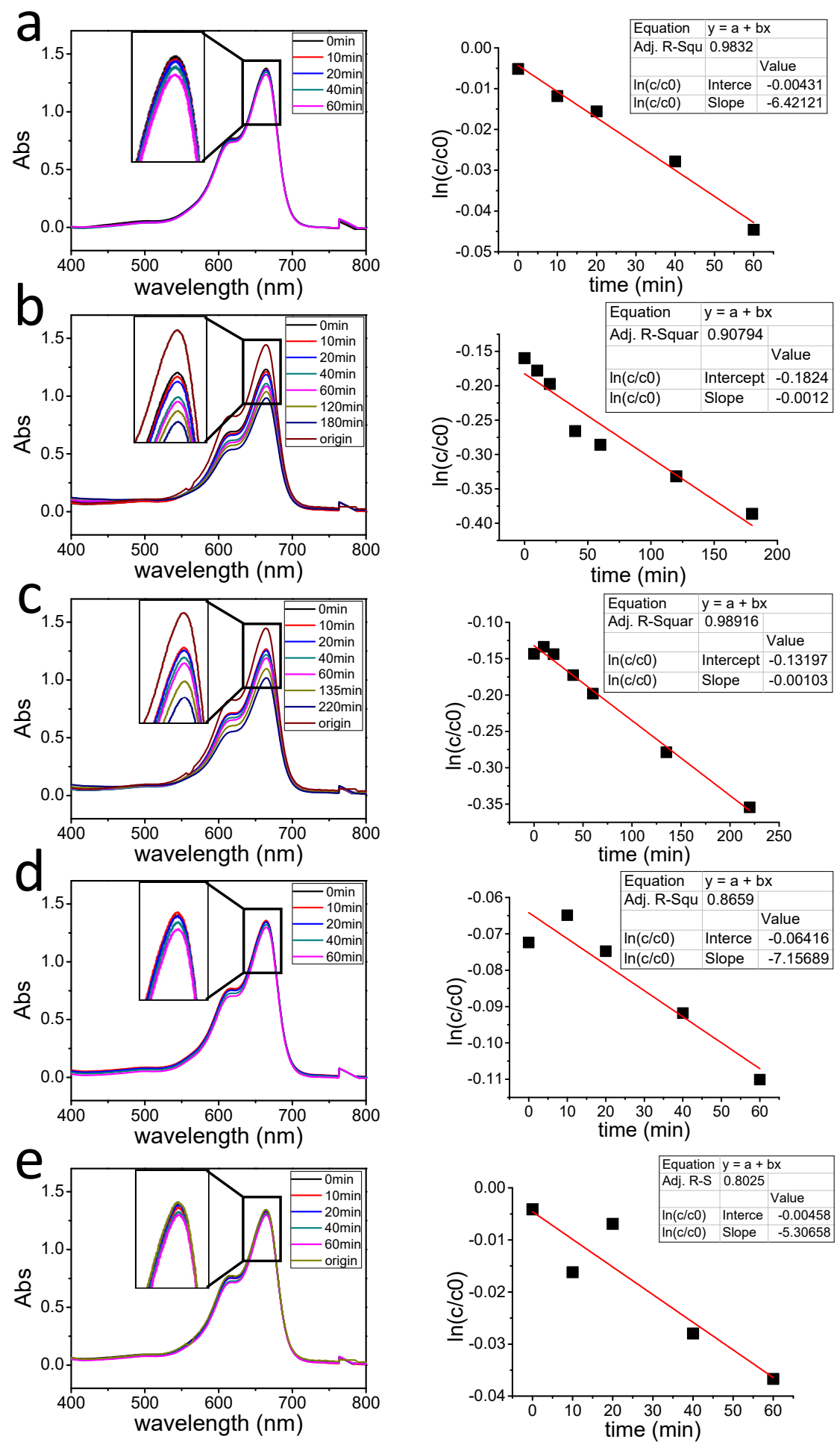

Figure 7. (a-e) UV-Vis spectra of degradation of MB under visible light irradiation. Their degradation rate K using Ag NPs sample 1-5 synthesized by (1) heating; (2-5) irradiating for $0.5 \mathrm{~h}, 1 \mathrm{~h}, 1.5 \mathrm{~h}, 2 \mathrm{~h}$. 
Table 1. Summary of synthesis methods, degradation rate $\mathrm{K}$ and average particle size.

\begin{tabular}{cccc}
\hline Sample & Synthesis Method & Degradation Rate K $\left(\mathbf{m i n}^{-\mathbf{1}}\right)$ & Average Particle Size (nm) \\
\hline 1 & By heating & 0.00064 & 71.43 \\
\hline 2 & Irradiating for $0.5 \mathrm{~h}$ & 0.0012 & 25.34 \\
\hline 3 & Irradiating for $1 \mathrm{~h}$ & 0.00103 & 32.88 \\
\hline 4 & Irradiating for $1.5 \mathrm{~h}$ & 0.000715 & 33.24 \\
\hline 5 & Irradiating for $2 \mathrm{~h}$ & 0.00053 & 40.73 \\
\hline
\end{tabular}

The plasmon-assisted photocatalytic activity of mixture of $\mathrm{Ag} \mathrm{NPs}$ and $\mathrm{TiO}_{2}$ nanowires was also evaluated by degradation of $\mathrm{MB}$ under UV and visible light. $\mathrm{TiO}_{2}$ nanowires without Ag NPs were used for degradation of $\mathrm{MB}$ as blank control. $\mathrm{TiO}_{2}$ absorbed photo energy and produced valance band holes and conduction band electrons, the valence band holes can react with water and produce $\bullet \mathrm{OH}$ radicals, which dominate the degradation of MB. Since the band gap energy of anatase phase $\mathrm{TiO}_{2}$ is $3.2 \mathrm{eV}$, it can only absorb UV irradiation. Thus, as shown in Figure 8a, under visible light, $\mathrm{TiO}_{2}$ nanowires have no photocatalytic activity. Different modification methods have been investigated to improve the visible light response of $\mathrm{TiO}_{2}$. Iodine doped $\mathrm{TiO}_{2}$ showed a considerable improvement in degradation of aqueous bisphenol A under visible light irradiation [46]. Similarly, nitrogen doped $\mathrm{TiO}_{2}$ also proved efficient for degradation of methyl orange (MO), the degradation efficiency was enhanced from 34 to $78 \%$ after $8 \mathrm{~h}$ sunlight irradiation [47]. The presence of $\mathrm{Ag}$ NPs on the surface of $\mathrm{TiO}_{2}$ and $\mathrm{N}-\mathrm{TiO}_{2}$ further improved the photo degradation percentage from 40 to $95 \%$. The degradation efficiency of $\mathrm{MB}$ under visible light was also investigated, chemical reduced $\mathrm{Ag} \mathrm{NPs}$ and $\mathrm{TiO}_{2}$ presented $30 \%$ degradation after 180 min visible light irradiation [48]. In Figure 8b, the green synthesized Ag NPs showed better photocatalytic activity, with 90 min visible light irradiation, the degradation percentage of $\mathrm{MB}$ reached about $30 \%$, and the calculated degradation rate was 0.0044 . The increasing photocatalytic activity of $\mathrm{TiO}_{2}$ can be attributed to two major roles of Ag NPs, promoting charge separation through the formation of Schottky junction and enhancing local electric through the LSPR effect [49]. The built-in potential in Schottky junction can promote the separation of photo-generated electron-hole pairs, which could strongly affect the degradation of MB. The high electronegativity of Ag NPs promotes the separation of photoinduced electron-hole pairs, the photogenerated electrons react directly with the oxygen adsorbed on the surface of $\mathrm{TiO}_{2}$ to produce oxygen radicals $\bullet \mathrm{O}_{2}{ }^{-}$, and the photogenerated holes can react with $\mathrm{H}_{2} \mathrm{O}$ to produce $\bullet \mathrm{OH}$ radicals. These reactions decreased the high recombination rate of $\mathrm{TiO}_{2}$ nanowires, therefore improving the photocatalytic activity of $\mathrm{TiO}_{2}$ under visible light irradiation [50]. While under sunlight, UV irradiation also played an important role in degradation of MB, Ag NPs also enhanced the photocatalytic activities of $\mathrm{TiO}_{2}$ by both trapped electrons and holes. Figure $\mathrm{S} 3$ showed the UV-Vis spectra and degradation rate of the mixture under UV light irradiation. After adding $\mathrm{Ag}$ NPs into the $\mathrm{TiO}_{2}$ and $\mathrm{MB}$ solution, the degradation rate increased from 0.09819 to 0.121 , which is consistent with experiment results using visible light irradiation of a previous study (Figure 8). It can be proposed that silver plasmonic photocatalysts working under a full solar spectrum can be obtained by preparation of various sizes of Ag NPs. 

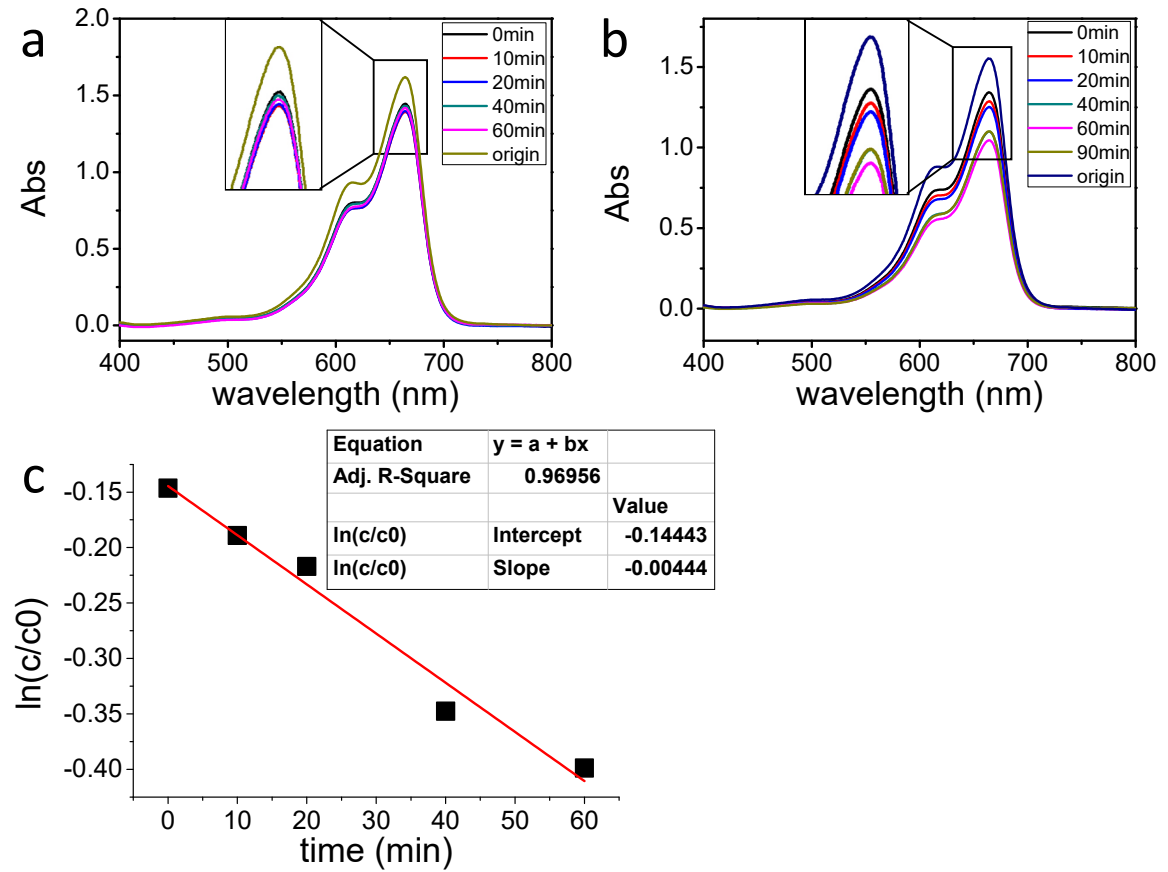

Figure 8. Degradation of $\mathrm{MB}$ under visible light radiation of (a) $\mathrm{TiO}_{2}$ nanowires only. (b) mixture of $\mathrm{TiO}_{2}$ nanowires and Ag NPs. (c) degradation rate of the mixture.

To further understand the photocatalytic mechanism of the mixture of Ag NPs and $\mathrm{TiO}_{2}$ nanowires, the main reactive species such as $\mathrm{h}^{+}, \bullet \mathrm{OH}$ and $\bullet \mathrm{O}_{2}{ }^{-}$were investigated during the photocatalytic oxidation process. Triethanolamine (TEOA), isopropanol (IPA) and $p$-benzoquinone (BQ) were used as scavengers for $\mathrm{h}^{+}, \bullet \mathrm{OH}$ and $\bullet \mathrm{O}_{2}{ }^{-}$, respectively. The degradation of MB with no quenchers under UV irradiation was used as the blank control, and the degradation efficiency was $99.5 \%$ after $1 \mathrm{~h}$ irradiation, as shown in Figure 9. It was found that when $1 \mathrm{~mL}$ IPA quencher was added, the degradation efficiency was significantly decreased to $32.6 \%$, while in the presence of TEOA and $B Q$, the degradation efficiencies were not quenched obviously. The result suggested that the degradation of $\mathrm{MB}$ by the mixture of Ag NPs and $\mathrm{TiO}_{2}$ could mainly be attributed to $\bullet \mathrm{OH}$, while $\mathrm{h}^{+}$and $\bullet \mathrm{O}_{2}{ }^{-}$ only played a relatively minor role in the whole degradation process. This is consistent with previous studies $[17,18]$. The generated main reactive species can be described as follows:

$$
\begin{gathered}
\mathrm{Ag} / \mathrm{TiO}_{2}+h v \rightarrow \mathrm{e}^{-}+\mathrm{h}^{+} \\
\mathrm{e}^{-}+\mathrm{O}_{2} \rightarrow \bullet \mathrm{O}_{2}{ }^{-} \\
\mathrm{h}^{+}+\mathrm{H}_{2} \mathrm{O} \rightarrow \mathrm{H}^{+}+\bullet \mathrm{OH} \\
\bullet \mathrm{O}_{2}^{-}+\mathrm{H}^{+} \rightarrow \bullet \mathrm{HO}_{2} \\
2 \bullet \mathrm{HO}_{2} \rightarrow \mathrm{H}_{2} \mathrm{O}_{2}+\mathrm{O}_{2} \\
\mathrm{H}_{2} \mathrm{O}_{2}+\mathrm{e}^{-} \rightarrow \bullet \mathrm{OH}+\mathrm{OH}^{-} \\
\mathrm{MB}+\left(\bullet \mathrm{OH}, \bullet \mathrm{O}_{2}^{-}, \mathrm{h}^{+}\right) \rightarrow \text { degradation products }
\end{gathered}
$$




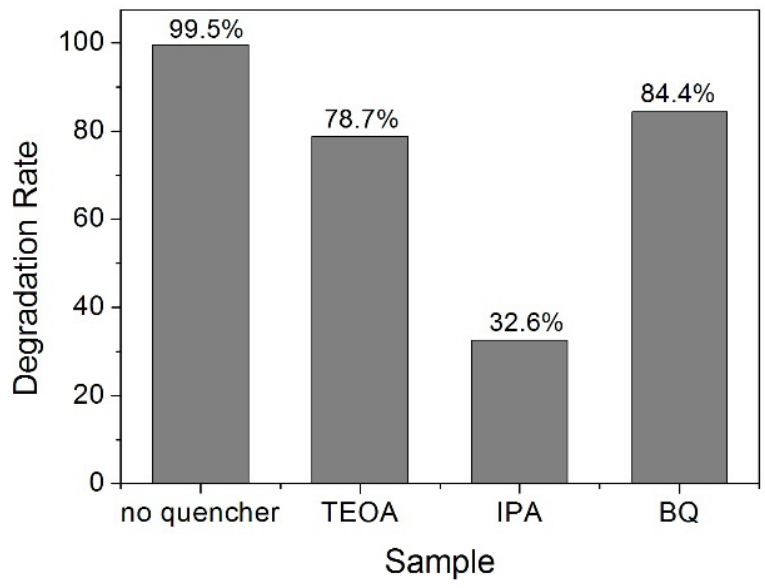

Figure 9. Degradation rate of $\mathrm{MB}$ with different quenchers by a mixture of $\mathrm{Ag} \mathrm{NPs}$ and $\mathrm{TiO}_{2}$ nanowires under UV irradiation for $1 \mathrm{~h}$.

During the reaction, $\mathrm{pH}$ of the solution was monitored using a $\mathrm{pH}$ meter at $10 \mathrm{~min}$ interval. Deionized water, pure $\mathrm{Ag} \mathrm{NPs}$ and $\mathrm{TiO}_{2}$ nanowires were also measured under the same irradiation for comparison. As shown in Figure 10, $\mathrm{pH}$ values of the solution decreased as the reaction time got longer. The reaction $\mathrm{pH}$ was generally consistent with the mixture of $\mathrm{TiO}_{2}$ and $\mathrm{Ag}$ NPs separately. The decreasing $\mathrm{pH}$ of the reaction solution indicated the increase in $\bullet \mathrm{OH}$ radicals.

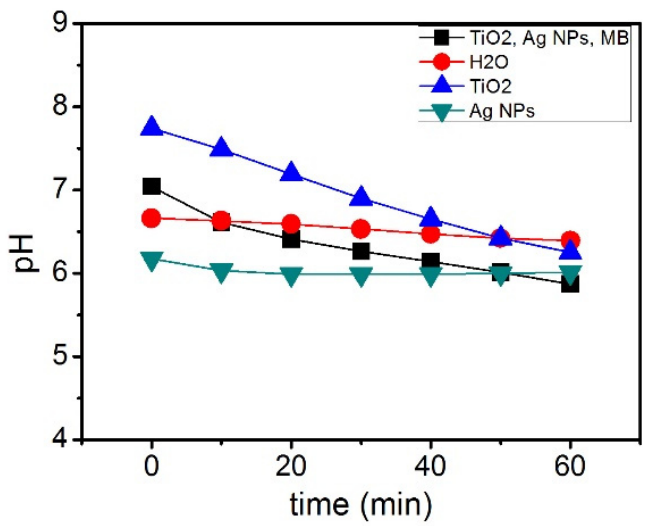

Figure 10. PH variation during a reaction with UV light irradiation.

As mentioned earlier, the main mechanism of Ag NPs degradation is dominated by free electrons from LSPR, the electron transfer is enhanced by the surface organic groups (as shown in Figure 3) around the Ag NPs and further generates $\bullet \mathrm{O}_{2}{ }^{-}$radicals, as shown in Equation (4), but this direct plasmonic degradation is not observed by Ag NPs synthesized by a conventional chemical method, such as using sodium citrate as a reducing agent [4]. According to Equation (5), the holes trapped by Ag nanoparticles can also attribute to the $\bullet \mathrm{OH}$ radical generation in $\mathrm{TiO}_{2}$ photocatalytic degradation, as shown in Figure 11 . The degradation mechanism of mixture of $\mathrm{Ag} \mathrm{NPs}$ and $\mathrm{TiO}_{2}$ nanowires thus involves two kinds of plasmonic enhanced photodegradation, one is the direct degradation of $\mathrm{MB}$ by electron transfer between organic groups and Ag NPs surface plasmonic electrons and the second is the enhancement of $\mathrm{TiO}_{2}$ degradation due to the e-h separation by Ag nanoparticles. Through SPR effect the conduction electrons of Ag was stimulated [51]. Dissolved oxygen molecules captured the excited surface electrons and produced hydroxyl radicals [52], which leaves positively charged Ag nanoparticles and is attracted to anionic MB dye. MB molecules can be oxidized by the created hydroxyl radicals. Furthermore, as an electron conductor Ag NPs can retard the recombination of electron-hole pairs [20,26], 
along with the LSPR it thus improved the degradation rate of MB. This evidence proved that the degradation mechanism of $\mathrm{MB}$ under visible light irradiation with $\mathrm{Ag}$ nanoparticleenhanced $\mathrm{TiO}_{2}$ nanowires is dominated by $\bullet \mathrm{OH}$ radicals.

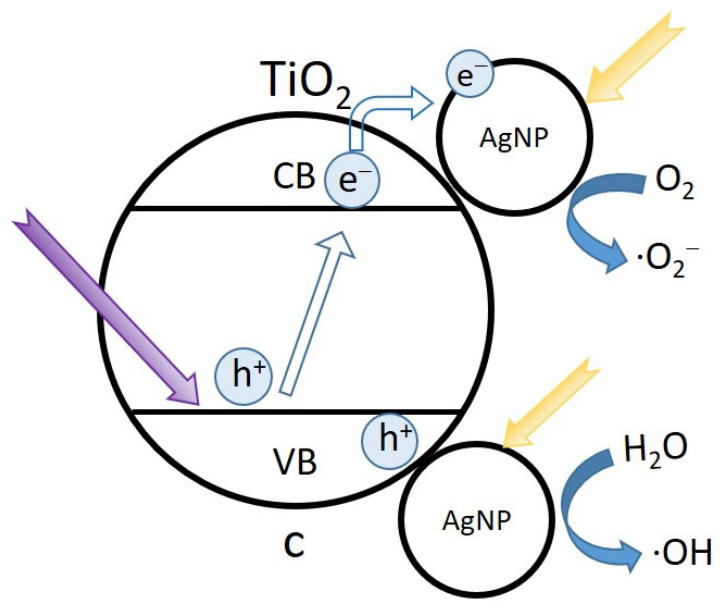

Figure 11. The main mechanism of $\mathrm{Ag} / \mathrm{TiO}_{2}$ plasmonic enhanced photocatalytic degradation.

\section{Materials and Methods}

\subsection{Materials}

Silver nitrate $\left(\mathrm{AgNO}_{3}\right)$, methylene blue $(\mathrm{MB})$, commercial P25, sodium hydroxide $(\mathrm{NaOH})$, and hydrochloric acid $(\mathrm{HCl}, 70 \%)$ was purchased from Fuchen Tianjin Chemical Reagents Factory, China. All chemicals were used without further purification. Green tea (Ti Kuan Yin) was purchased from a local market. Unless otherwise stated, deionized water was used in all of the experiments. $1 \mathrm{~g}$ of green tea was washed using deionized water and boiled with $1 \mathrm{~L}$ of deionized water at $373 \mathrm{~K}$ for an hour. The extract was then filtered and stored at $4^{\circ} \mathrm{C}$ in a fridge for further experimentation.

\subsection{Synthesis of $A g N P S$}

Aqueous solution of $\mathrm{AgNO}_{3}$ was prepared using deionized water at a concentration of $100 \mathrm{mmol} / \mathrm{L} .1 \mathrm{~mL} \mathrm{AgNO}_{3}$ solution was added into $20 \mathrm{~mL}$ freshly prepared tea extract, and then made the mixture up to $100 \mathrm{~mL}$ with deionized water. Five copies of this solution was made and labeled sample $1-5$, Sample 1 was put in a water bath at $80{ }^{\circ} \mathrm{C}$ for an hour, samples 2-5 were irradiated under a $500 \mathrm{~W}$ xenon lamp (PL-XQ 500W, Beijing, China) with a UV filter for $0.5 \mathrm{~h}, 1 \mathrm{~h}, 1.5 \mathrm{~h}$ and $2 \mathrm{~h}$ respectively, the distance between the light and the sample was $20 \mathrm{~cm}$. A brown-yellow solution was formed indicating the formation of Ag NPs. The solution was concentrated in a centrifugal machine at $8000 \mathrm{rps}$ for $10 \mathrm{~min}$, the extra tea extract, was then removed the sediments washed with deionized water and the solution concentrated again. The sediments were dried under $50^{\circ} \mathrm{C}$ to obtain the Ag NPs.

\subsection{Characterization}

The synthesized Ag NPs were dispersed in deionized water for UV-Visible absorption test using UV-Visible spectroscopy (METASH UV-9000s, Shanghai, China). The spectra were recorded using an UV-Vis Analyst from 200 to $800 \mathrm{~nm}$. Deionized water was used as the baseline. The X-ray diffraction (XRD) analysis of Ag NPs was carried out by the D8 Advances Brucker instrument in transmission mode with $\mathrm{Cu} \mathrm{K} \alpha$ radiation $(\lambda=0.154 \mathrm{~nm})$ (D8 Advances Brucker, Germany). Scanning was performed in the region of $2 \theta$ from $20^{\circ}$ to $80^{\circ}$. The morphology and size of the synthesized Ag NPs were investigated by Scanning Electron Microscopy (Hitachi S-4800, Tokyo, Japan). The XPS data were taken on an AXIS-Ultra instrument from Kratos Analytical using monochromatic $\mathrm{Al} \mathrm{K \alpha}$ radiation $(225 \mathrm{~W}, 15 \mathrm{~mA}, 15 \mathrm{kV})$ and low-energy electron flooding for charge compensation (Kratos Analytical, Manchester, UK). To compensate for surface charges effects, binding energies were calibrated using C $1 \mathrm{~s}$ hydrocarbon peak at $284.80 \mathrm{eV}$. SEM and XPS samples were 
prepared by dropping the nanoparticle solution onto silicon wafers and dried at room temperature prior to measurement.

\subsection{Photocatalytic Degradation of Dye}

The photocatalytic activity of the synthesized Ag NPs was evaluated by degradation of MB under UV and visible radiation respectively. $0.02 \mathrm{mmol} / \mathrm{L}$ of $\mathrm{MB}$ was added to $1000 \mathrm{~mL}$ deionized water maintaining a concentration of $0.02 \mathrm{mmol} / \mathrm{L}$. About $5 \mathrm{mg}$ of synthesized Ag NPs sample 1-5 was added to $100 \mathrm{~mL}$ of the MB solution respectively. Before irradiation, the suspensions were magnetically stirred for $30 \mathrm{~min}$ in the dark to make sure the solutions reached equilibrium. Then the solutions with sample 1-5 were put under a sunlight simulator with a UV filter cut-off at $450 \mathrm{~nm}$ for $60 \mathrm{~min}$ or more. MB concentration was monitored by UV-Vis absorption spectra. About $5 \mathrm{mg}$ of Ag NPs was mixed with $100 \mathrm{mg} \mathrm{TiO}{ }_{2}$ nanowires and stirred in $100 \mathrm{~mL}$ MB solution in the dark for $30 \mathrm{~min}$. $\mathrm{TiO}_{2}$ nanowires were prepared by the hydrothermal method using commercial P25 [53]. The detailed synthesize process was demonstrated in Supplementary Materials. Then the solutions were irradiated by UV and visible light respectively, and the UV-Vis spectra were recorded to monitor concentration of MB. During the reaction, $\mathrm{pH}$ was also monitored by a $\mathrm{pH}$ meter (INESA PHS-3C, Shanghai, China), and all the measurements of the solution were carried out at a constant temperature of $25^{\circ} \mathrm{C}$. The solution without $\mathrm{Ag}$ NPs, deionized water, and solution without MB were also measured as a blank control.

\section{Conclusions}

In this study, Ag NPs was synthesized by heating up to $80^{\circ} \mathrm{C}$ and by visible light irradiation using tea extract as a reduction agent. When the reduction was under visible light for different times, it would affect the particle size and photocatalytic activity. The longer they were under visible light irradiation, the larger the particle size was, and the lesser the photocatalytic activity was. Ag NPs can also improve the photocatalytic ability of $\mathrm{TiO}_{2}$ nanowires, with higher degradation rate $\mathrm{K}$ under both $\mathrm{UV}$ and visible irradiations. The degradation rate reached 0.121 under UV irradiation. The catalytic enhancement mechanism of $\mathrm{TiO}_{2}$ nanowires under visible light irradiation was demonstrated. The high yield of $\bullet \mathrm{OH}$ radicals plays a dominate role in the plasmonic enhanced photodegradation of dye molecules. Therefore, Ag NPs mixed with $\mathrm{TiO}_{2}$ nanowires may be used as highly stable and effective photocatalysts. The green synthesized Ag NPs showcase a highly significant advancement towards the development of an eco-friendly method.

Supplementary Materials: The following are available online at https:/ / www.mdpi.com/article/10 .3390/catal11121499/s1, Figure S1: SEM patterns of Ag NPs., Figure S2: Binding Energy of Ag 3d, Figure S3: Degradation of MB under UV radiation of (a) TiO2 nanowires only. (b) mixture of $\mathrm{TiO} 2$ nanowires and Ag NPs, Figure S4: (a) SEM pattern of the prepared $\mathrm{TiO}_{2}$ nanowires, (b) XRD pattern of the prepared $\mathrm{TiO}_{2}$ nanowires.

Author Contributions: Conceptualization, Y.M. and A.H.; methodology, Y.M.; investigation, Y.M.; data curation, L.T.; writing—original draft preparation, Y.M.; writing-review and editing, Y.M., S.B. and A.H.; project administration, Y.M. All authors have read and agreed to the published version of the manuscript.

Funding: This research is funded by the China Postdoctoral Science Foundation, grant number 230210641.

Acknowledgments: This research is also supported by the Beige Institute, grant number KH54-2827-01.

Conflicts of Interest: The authors declare no conflict of interest.

\section{References}

1. Tan, L.L.; Wei, M.; Shang, L.; Yang, Y.W. Cucurbiturils-mediated noble metal nanoparticles for applications in sensing, sers, theranostics, and catalysis. Adv. Funct. Mater. 2021, 31, 2007277. [CrossRef]

2. Hu, A.; Li, R.; Bai, S.; Yu, Y.; Zhou, W.; Bridges, D.; Zhang, L. Introduction to Laser Micro-to-Nano Manufacturing. In Laser Micro-Nano-Manufacturing and 3D Microprinting; Springer International Publishing: Cham, Switzerland, 2020; pp. 1-74.

3. Siegel, J. Progressive approach for metal nanoparticle synthesis. Mater. Lett. 2012, 89, 47-50. [CrossRef] 
4. Hu, A.; Guo, J.Y.; Alarifi, H. Low temperature sintering of Ag nanoparticles for flexible electronics packaging. Appl. Phys. Lett. 2010, 97, 153117. [CrossRef]

5. Yan, J.F.; Zou, G.S.; Hu, A. Preparation of PVP coated Cu NPs and the application for low-temperature bonding. J. Mater. Chem. 2011, 21, 15981-15986.

6. Klaus, T.; Joerger, R.; Olsson, E. Silver-based crystalline nanoparticles, microbially fabricated. Proc. Natl. Acad. Sci. USA 1999, 96, 13611-13614. [CrossRef] [PubMed]

7. Javaid, A. Diversity of bacterial synthesis of silver nanoparticles. BioNanoScience 2018, 8, 43-59. [CrossRef]

8. Khan, A.U. Fungi-assisted silver nanoparticle synthesis and their applications. Bioprocess Biosyst. Eng. 2018, 41, 1-20. [CrossRef] [PubMed]

9. Osorio-Echavarría, J. Synthesis of silver nanoparticles using white-rot fungus Anamorphous Bjerkandera sp. R1: Influence of silver nitrate concentration and fungus growth time. Sci. Rep. 2021, 11, 1-14. [CrossRef]

10. Du, L.; Xu, Q.; Huang, M. Synthesis of small silver nanoparticles under light radiation by fungus Penicillium oxalicum and its application for the catalytic reduction of methylene blue. Mater. Chem. Phys. 2015, 160, 40-47. [CrossRef]

11. Oluwafemi, O.S.; Mochochoko, T.; Leo, A.J.; Mohan, S.; Jumbam, D.N.; Songca, S.P. Microwave irradiation synthesis of silver nanoparticles using cellulose from Eichhornia crassipes plant shoot. Mater. Lett. 2016, 185, 576-579. [CrossRef]

12. Jayaprakash, N. Green synthesis of Ag nanoparticles using Tamarind fruit extract for the antibacterial studies. J. Photochem. Photobiol. B Biol. 2017, 169, 178-185. [CrossRef] [PubMed]

13. Roy, K.; Sarkar, C.K.; Ghosh, C.K. Photocatalytic activity of biogenic silver nanoparticles synthesized using potato (Solanum tuberosum) infusion. Spectrochim. Acta Part A Mol. Biomol. Spectrosc. 2015, 146, 286-291. [CrossRef] [PubMed]

14. Karuppiah, M.; Rajmohan, R. Green synthesis of silver nanoparticles using Ixora coccinea leaves extract. Mater. Lett. 2013, 97, 141-143. [CrossRef]

15. Mo, Y.-Y. Green synthesis of silver nanoparticles using eucalyptus leaf extract. Mater. Lett. 2015, 144, 165-167. [CrossRef]

16. Ahmadi, S. Anti-bacterial/fungal and anti-cancer performance of green synthesized Ag nanoparticles using summer savory extract. J. Exp. Nanosci. 2020, 15, 363-380. [CrossRef]

17. Hu, A.; Liang, R.; Zhang, X. Enhanced photocatalytic degradation of dyes by $\mathrm{TiO}^{2}$ nanobelts with hierarchical structures. J. Photochem. Photobiol. A Chem. 2013, 256, 7-15. [CrossRef]

18. Liang, R.; Hu, A.; Hatat-Fraile, M. Development of $\mathrm{TiO}^{2}$ Nanowires for Membrane Filtration Applications. In Nanotechnology for Water Treatment and Purification; Hu, A., Allen, A., Eds.; Springer International Publishing: Cham, Switzerland, 2014 ; pp. 47-77.

19. Asahi, R. Nitrogen-doped titanium dioxide as visible-light-sensitive photocatalyst: Designs, developments, and prospects. Chem. Rev. 2014, 114, 9824-9852. [CrossRef]

20. Jafari, S.; Zhao, F.; Zhao, D. A comparative study for the removal of methylene blue dye by $\mathrm{N}$ and $\mathrm{S}$ modified TiO ${ }^{2}$ adsorbents. $J$. Mol. Liq. 2015, 207, 90-98. [CrossRef]

21. Yu, S. Carbon-doped $\mathrm{TiO}^{2}$ nanoparticles wrapped with nanographene as a high performance photocatalyst for phenol degradation under visible light irradiation. Appl. Catal. B Environ. 2014, 144, 893-899. [CrossRef]

22. Bayan, E.M. Fluorine-doped titanium dioxide: Synthesis, structure, morphology, size and photocatalytic activity. In Advanced Materials; Springer International Publishing: Cham, Switzerland, 2017; pp. 17-24.

23. Kondo, K. Development of highly efficient sulfur-doped $\mathrm{TiO}^{2}$ photocatalysts hybridized with graphitic carbon nitride. Appl. Catal. B Environ. 2013, 142, 362-367. [CrossRef]

24. Li, W.; Liang, R.; Hu, A. Generation of oxygen vacancies in visible light activated one-dimensional iodine $\mathrm{TiO}^{2}$ photocatalysts. RSC Adv. 2014, 4, 36959-36966. [CrossRef]

25. Jiang, B. A facile and green synthesis route towards two-dimensional TiO²@Ag heterojunction structure with enhanced visible light photocatalytic activity. Crystengcomm 2013, 15, 648-657. [CrossRef]

26. Awazu, K.; Fujimaki, M.; Rockstuhl, C. A plasmonic photocatalyst consisting of silver nanoparticles embedded in titanium dioxide. J. Am. Chem. Soc. 2008, 130, 1676-1680. [CrossRef] [PubMed]

27. Sohrabnezhad, S.; Seifi, A. The green synthesis of Ag/ZnO in montmorillonite with enhanced photocatalytic activity. Appl. Surf. Sci. 2016, 386, 33-40. [CrossRef]

28. Vidhu, V.K.; Philip, D. Catalytic degradation of organic dyes using biosynthesized silver nanoparticles. Micron 2014, 56, 54-62. [CrossRef]

29. Hu, A.; Peng, P.; Alarifi, H. Femtosecond laser welded nanostructures and plasmonic devices. J. Laser Appl. $2012,24,042001$. [CrossRef]

30. Shi, X. Plasmon-enhanced photocurrent generation and water oxidation with a gold nanoisland-loaded titanium dioxide photoelectrode. J. Phys. Chem. C 2013, 117, 2494-2499. [CrossRef]

31. Tanaka, A.; Sakaguchi, S.; Hashimoto, K.; Kominami, H. Preparation of Au/ $\mathrm{TiO}^{2}$ with metal cocatalysts exhibiting strong surface plasmon resonance effective for photoinduced hydrogen formation under irradiation of visible light. ACS Catal. 2013, 3, 79-85. [CrossRef]

32. Nanaji, K.; Janardhana, R.K.S.K.; Rao, T.N.; Anandan, S. Energy level matching for efficient charge transfer in Ag doped-Ag modified $\mathrm{TiO}^{2}$ for enhanced visible light photocatalytic activity. J. Alloy. Compd. 2019, 794, 662-671. [CrossRef]

33. Sadeghi, B.; Gholamhoseinpoor, F. A study on the stability and green synthesis of silver nanoparticles using Ziziphora tenuior (Zt) extract at room temperature. Spectrochim. Acta Part A Mol. Biomol. Spectrosc. 2015, 134, 310-315. [CrossRef] [PubMed] 
34. Jagtap, U.B.; Bapat, V.A. Green synthesis of silver nanoparticles using Artocarpus heterophyllus Lam. Seed extract and its antibacterial activity. Ind. Crop. Prod. 2013, 46, 132-137. [CrossRef]

35. Bai, S.; Zhou, W.; Lin, Y. Ultraviolet pulsed laser interference lithography and application of periodic structured Ag-nanoparticle films for surface-enhanced Raman spectroscopy. J. Nanoparticle Res. 2014, 16, 1-14. [CrossRef]

36. Mie, G. Contribution to the optical properties of turbid media, in particular of colloidal suspensions of metals. Ann. Phys. 1908, 25, 377-452. [CrossRef]

37. Shankar, S.; Rai, A.; Ahmad, A. Rapid synthesis of Au, Ag, and bimetallic Au core-Ag shell nanoparticles using Neem (Azadirachta indica) leaf broth. J. Colloid Interface Sci. 2004, 275, 496-502. [CrossRef]

38. Vanaja, M.; Paulkumar, K.; Baburaja, M. Degradation of methylene blue using biologically synthesized silver nanoparticles. Bioinorg. Chem. Appl. 2014, 2014, 742356-742364. [CrossRef] [PubMed]

39. Horžić, D.; Komes, D.; Belščak, A. The composition of polyphenols and methylxanthines in teas and herbal infusions. Food Chem. 2009, 115, 441-448. [CrossRef]

40. Konieczynski, P.; Wesolowski, M. Phytate, inorganic and total phosphorus and their relations to selected trace and major elements in herbal teas. Acta Pol. Pharm. 2014, 71, 85-93. [PubMed]

41. Aoshima, H.; Hirata, S.; Ayabe, S. Antioxidative and anti-hydrogen peroxide activities of various herbal teas. Food Chem. 2007, 103, 617-622. [CrossRef]

42. Romand, M.; Roubin, M.; Deloume, J.P. ESCA studies of some copper and silver selenides. J. Electron Spectrosc. Relat. Phenom. 1978, 13, 229-242. [CrossRef]

43. Lee, S.H.; Jo, J.S.; Park, J.H.; Lee, S.W.; Jang, J.W. A hot-electron-triggered catalytic oxidation reaction of plasmonic silver nanoparticles evidenced by surface potential mapping. J. Mater. Chem. A 2018, 6, 20939-20946. [CrossRef]

44. Kadam, J.; Dhawal, P.; Barve, S.; Kakodkar, S. Green synthesis of silver nanoparticles using cauliflower waste and their multifaceted applications in photocatalytic degradation of methylene blue dye and $\mathrm{Hg} 2+$ biosensing. SN Appl. Sci. 2020, 2, 738. [CrossRef]

45. Liang, R.; Hu, A.; Li, W. Enhanced degradation of persistent pharmaceuticals found in wastewater treatment effluents using TiO ${ }^{2}$ nanobelt photocatalysts. J. Nanoparticle Res. 2013, 15, 1-13. [CrossRef]

46. Kuo, C.-Y.; Hsiao, H.-M. Preparation of iodine doped titanium dioxide to photodegrade aqueous bisphenol A under visible light. Process. Saf. Environ. Prot. 2015, 95, 265-270. [CrossRef]

47. Madhavi, V.; Kondaiah, P. Influence of silver nanoparticles on titanium oxide and nitrogen doped titanium oxide thin films for sun light photocatalysis. Appl. Surf. Sci. 2018, 436, 708-719.

48. Salomatina, E.V. Preparation and photocatalytic properties of titanium dioxide modified with gold or silver nanoparticles. $J$. Environ. Chem. Eng. 2021, 9.5, 106078. [CrossRef]

49. Lee, J.E.; Bera, S.; Choi, Y.S.; Lee, W.I. Size-dependent plasmonic effects of M and M@ SiO2 (M= Au or Ag) deposited on TiO² in photocatalytic oxidation reactions. Appl. Catal. B Environ. 2017, 214, 15-22. [CrossRef]

50. Kowalska, E. Silver-modified titania with enhanced photocatalytic and antimicrobial properties under UV and visible light irradiation. Catal. Today 2015, 252, 136-142. [CrossRef]

51. Yu, L.; Xi, J.; Li, M.-D.; Chan, H.T. The degradation mechanism of methyl orange under photo-catalysis of TiO ${ }^{2}$. Phys. Chem. Chem. Phys. 2012, 14, 3589-3595. [CrossRef]

52. Mahmoud, M.A.; Poncheri, A.; Badr, Y. Photocatalytic degradation of methyl red dye. S. Afr. J. Sci. 2009, 105, 299-303. [CrossRef]

53. $\mathrm{Hu}, \mathrm{A} . ;$ Zhang, X.; Oakes, K.D. Hydrothermal growth of free standing $\mathrm{TiO}^{2}$ nanowire membranes for photocatalytic degradation of pharmaceuticals. J. Hazard. Mater. 2011, 189, 278-285. [CrossRef] 